\title{
CROSS THE BORDER - CLOSE THE GAP: RESILIENCE-BASED ANALYSIS OF LANDSCAPE CHANGE (EDITORIAL)
}

\author{
Claudia Bieling ${ }^{1}$, Tobias Plieninger ${ }^{2}$, Kathrin Trommler $^{3}$
}

Received 29 March 2011; Accepted 23 September 2011

\begin{abstract}
As a consequence of widespread agricultural intensification, land abandonment and urbanization, most European landscapes are undergoing fundamental changes. The drivers and effects of these dynamics and possible approaches for guiding them (or at least coping with them) are addressed by two relatively distinct research communities dealing with the concepts of "cultural landscapes" and "resilience". This editorial introduces the key elements of the resilience approach and illustrates these in a landscape-related context. Incorporating the resilience perspective into landscape research sheds light on drivers and patterns of landscape change and illustrates opportunities for its constructive management. This will be dealt with in detail in the following three contributions to this special issue.
\end{abstract}

Keywords: Landscape change, resilience, interdisciplinarity, cultural landscapes, driving forces, land management

Zusammenfassung: Durch die Trends zur landwirtschaftlichen Intensivierung, der Aufgabe der Landwirtschaft und der Urbanisierung sind viele Landschaften in Europa mit einem tiefgreifenden Wandel konfrontiert. Die Triebkräfte und Auswirkungen dieser Dynamik und mögliche Wege diese zu steuern (oder die Effekte zumindest bewältigen zu können) stehen im Mittelpunkt von zwei voneinander abgrenzten wissenschaftlichen Gemeinden, die sich auf die Konzepte der „Kulturlandschaft“ sowie der "Resilienz" beziehen. Dieser Leitartikel führt in die Kernelemente des Ansatzes der Resilienz ein und illustriert inn in einem landschaftsbezogenen Kontext. Die Resilienz-Perspektive ermöglicht vielfältige Einblicke in die Ursachen und Muster von Landschaftswandel und skizziert Möglichkeiten, mit diesem auf konstruktive Weise umzugehen. Dies wird im Rahmen der drei folgenden Beiträge dieser Sonderausgabe im Detail beleuchtet.

Schlüsselwörter: Landschaftswandel, Resilienz, Interdisziplinarität, Kulturlandschaften, Triebkräfte, Landmanagement

\footnotetext{
${ }^{1}$ Claudia Bieling, Dr., Institute for Landscape Management, University of Freiburg, Tennenbacher Str. 4, D - 79106 Freiburg (Germany); E-Mail: claudia.bieling@landespflege.uni-freiburg.de.

${ }^{2}$ Tobias Plieninger, Dr., Berlin-Brandenburg Academy of Sciences and Humanities, Jägerstraße 22/23, D - 10117 Berlin (Germany); E-Mail: plieninger@bbaw.de

${ }^{3}$ Kathrin Trommler, Berlin-Brandenburg Academy of Sciences and Humanities, Jägerstraße 22/23, D - 10117 Berlin (Germany); E-Mail: trommler@bbaw.de
} 


\section{Landscapes in change}

The past decades have witnessed expanding interest in the protection, management and planning of cultural landscapes on the part of scientists, policy makers and the general public. This is reflected most prominently in the ratification of the European Landscape Convention by almost all European countries. These extensive efforts appear to be motivated by widespread concern about rapidly changing landscapes, including the alteration or loss of many familiar and valued features, for example of dense hedgerow networks (Zimmermann, 2006), mountain grassland (Bieling et al., 2010) and terraced vineyards (Höchtl et al., 2009) (Fig. 1).

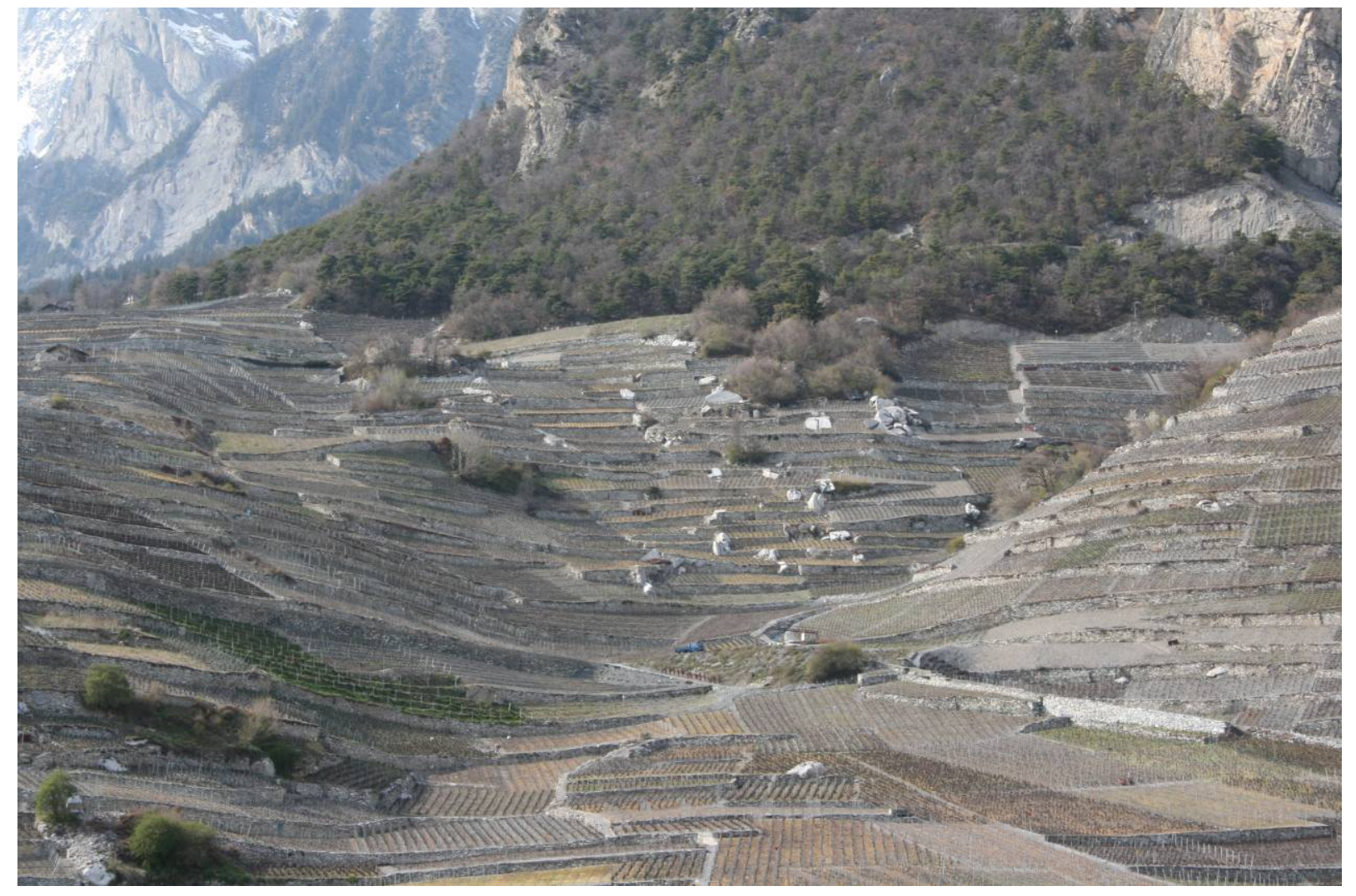

Fig 1. Terraced vineyard near Chamosons, Valais, Switzerland. Terraced vineyards are impressive testimonies of sophisticated land use practices and provide a rich biodiversity. However, under current conditions they are rarely profitable, and many terraced vineyards have already been given up (Picture: Claude Petit).

The relationship between people and their natural surroundings is complex. Landscapes can be seen along a gradient ranging from an absence of human influence (presumed for 'natural landscapes') to a high degree of human impact. Over millennia, people and their activities have shaped and sculpted landscapes with a distinctly human touch. At least in Europe, wilderness as such hardly exists. Given the long-lasting, comprehensive and spatially expansive human land use history, almost the entire land surface of the continent is considered to be cultural landscape: marked by different stages of anthropogenic influence which have been overlaid, refined or replaced by each other. People and land have become inseparable, with the latter now being considered inherently worthy of protection (Figueroa \& Aronson, 2006). A result of these interactions has been the gradual development of heterogeneous, 'multifunctional landscapes' in which traditional practices sustain a range of economic, social and environmental services as well as elevated levels of biodiversity (Jones-Walters, 2008). In the first report on 'Europe's Environment' published by the European Environment Agency in 1995, the overall value of landscapes was recognized as follows: "The richness and diversity of rural landscapes in Europe is a distinctive feature of the continent. There is probably nowhere else where the signs of human interaction with nature in landscape are so varied, contrasting and localised" (Stanners \& Bourdeau, 1995). Among their many important values and functions, these cultural landscapes are particularly appreciated for: enabling sustainable use of natural resources; 
serving as wildlife habitats; providing economic benefits, scenery and open spaces; and possessing cultural heritage.

Cultural landscapes result from sometimes gradual, sometimes rapid reorganizations of the environment in order to better adapt its uses and spatial structure to changing societal demands (Antrop, 2005). Hence, dynamic interactions between natural and cultural forces have brought about constant landscape change throughout history. However, over the past 200 years, the magnitude of landscape change has greatly increased and often caused irreversible damages, for example, drainage projects allowing for the agricultural use of fenlands and other hydrophilic land, or the focus on a small number of varieties and species in agriculture which has resulted in an irrecoverable loss of biodiversity. In the past 50 to 60 years, the speed, scale, frequency and magnitude of landscape changes in Europe have been unprecedented (Vos \& Klijn, 2000; Antrop, 2004, 2005). A whole set of ubiquitous 'drivers of change' - including demographic, macro-economic and socio-cultural changes -has fundamentally reshaped previously prevailing landscapes (Selman \& Knight, 2006). Particularly traditional practices characterized by small spatial scales, mixed cultures, low-input practices and multiple ecosystem services have been abandoned and replaced by standardized and simplified land uses. Within this overarching process, three different pathways can be distinguished:

\section{Agricultural intensification and upscaling}

Pressures to optimize crop quality and productivity have triggered agricultural intensification and an increase in the scale of production, particularly affecting the most productive European landscapes, e.g. coastal and river lowlands, wetlands and fertile plains. Intensification refers to a steady rise in the input of production factors (e.g. fertilizers, concentrated feeds, pesticides and agricultural machinery) and/or in the output of farm products (e.g. cereal or animal production) per area (Kristensen, 2001). Inputs of labour have been substituted by increased capital inputs, with 'high input-high output' systems as a result. Agricultural upscaling or concentration refers to a rising proportion of total productive resources (especially labour, capital and soil) or farm outputs becoming consolidated in the hands of a smaller number of producers (Walford, 2003). As a result of realising 'economies of scale', the total number of European farm enterprises has continually decreased, while farm size has increased. Intensification and upscaling have been facilitated both through technological progress and through national and European Union (EU) agricultural policies.

\section{Agricultural extensification and land abandonment}

In many remote and mountainous areas of Europe, where unfavourable soils, slopes, climatic factors, political barriers, and obstacles to transportation and distribution have prevented intensification, agriculture has been - and still is - in decline, and land has often been completely abandoned. Extensification means downgrading land use to a lower category of production (e.g. from agriculture to forestry or from commercial farming to hobby farming) by reducing input levels of capital, labour and other production factors. In land abandonment, the most extreme form of extensification, land goes out of production completely (Grove \& Rackham, 2001).

\section{Urban and infrastructural sprawl}

Cities, towns and traffic infrastructure have expanded across many landscapes (Vos \& Klijn, 2000). Urbanisation, described as "a complex process that transforms the rural or natural landscapes into urban and industrial ones forming star-shaped spatial patterns controlled by the physical conditions of the site and its accessibility by transportation routes" (Antrop, 2000: 257), has expanded almost exponentially since the end of the 19th century, when, among other changes, new modes of transportation were introduced. In the landscape, urbanisation takes the form of commuter settlements, recreational facilities, urban building styles, motorways, power lines, etc. 
In the face of these changes, efforts are being made all over the world to preserve landscapes in their actual state. Though some of these efforts have proven successful, large-scale land-use and subsequent landscape changes appear to be inevitable. In this context, it is important to note that ecosystem services and human well-being may be both degraded and enhanced through landscape change associated with extensification, intensification and urbanization. Typical trade-offs involve increases in commodity provisioning services at the cost of regulating, cultural and supporting services. However, care must be taken to avoid drawing overly hasty conclusions. For instance, even so-called 'degraded' landscapes may support high degrees of biodiversity (Plieninger \& Gärtner, 2011). Therefore, understanding the drivers of landscape change and its concrete effects and benefits on the various landscape features, as well as identifying possible approaches for managing change for biodiversity and human wellbeing, are both very pressing and difficult tasks on the agenda of land-use related science, policy and management. Here, the resilience approach may offer valuable insights.

\section{The resilience approach}

Through a systems theory perspective, the processes of, and the management goals for, landscape change can be brought into line with the concept of resilience. Resilience is defined as 'the capacity of a system to experience shocks while retaining essentially the same function, structure, feedbacks, and therefore identity' (Walker et al., 2006). In other words: Resilience means the ability to deal with disturbances or change without altering the essential characteristics of the system in question. Only once certain thresholds are exceeded do profound changes occur, making reorganisation necessary. The resilience approach focuses on the dynamics of change and how to adapt to and shape change.

This basic concept is applied to many different topics and contexts, ranging from ecology over materials sciences to security policy. It is increasingly being taken up in the study of natural resource use and management, i.e. with a focus on systems which are shaped through both natural and human components and influences. The increasing interest in the resilienceoriented study of ecosystems explicitly integrating the human realm becomes evident in the rapidly expanding number of publications dedicated to this topic. This results in an overwhelming array of books (for a profound introduction see Walker \& Salt, 2006b) and journal articles, some of them published in the research community's own and broadly renowned open-access journal 'Ecology and Society' (http://www.ecologyandsociety.org). A number of researchers and practitioners with different disciplinary backgrounds form the Resilience Alliance, a network which aims to explore the dynamics of social-ecological systems (see http://www.resalliance.org). The international Stockholm Resilience Centre advances transdisciplinary research, especially with regards to the governance of socialecological systems (http://www.stockholmresilience.org). Conferences on resilience, e.g. in the context of global change and sustainability, attract great attention ${ }^{4}$.

As resilience can refer to many different contexts, it is important to define resilience in terms of 'resilience of what to what' (Carpenter et al., 2001), for example the resilience of a Mediterranean terraced landscape to the abandonment of crop cultivation. There are some central notions of the resilience concept as applied to integrated systems of people and the natural environment:

\section{Social-ecological systems}

So far, the terms 'landscape' or 'cultural landscapes' have rarely been used in the resilience community. Instead, frequently used terms are 'coupled human and natural systems' or 'socialecological systems' (SES), understood as integrated systems in which people closely interact with natural components. This implies the notion of sub-systems at multiple scales, characterized by the specific interplay of patterns such as soil quality, water supply, population density or consumer demand. The resilience perspective is embedded in a wider research

\footnotetext{
${ }^{4}$ (http://resilience2011.org).
} 
community that has formed around the so-called 'ecosystem approach', expressed for example in the Millennium Ecosystem Assessment (2005).

\section{Drivers, thresholds, regime shifts}

The backbone of the resilience approach is the rich description of the system's determining variables or driving forces. Special attention is given to the spatial and temporal scales on which these act. Most variables driving social-ecological systems are slow, for example climate, landuse or human values, but there are also fast variables such as fire events, sudden toxic pollution, or social revolutions. It is assumed that social-ecological systems are able to cope with disturbances (e.g. demographic or economic changes in the case of cultural landscapes) without changing their structure or functions until they cross thresholds which are specific for each variable or the combination of different variables. Beyond these thresholds, disturbances can no longer be cushioned and the system shifts to another state, referred to as a regime shift. This may include negative effects, i.e. a degradation of ecosystem services in the case of cultural landscapes. For instance, a lake may be able to cope with pollution up to a certain point. Passing this threshold, it can suddenly jump into a state where most of the benefits so far provided - ranging from drinking water supply, over a habitat function for a variety of species, to recreational uses - drop out. Typically, it is very difficult or even impossible to reverse such regime shifts (Scheffer \& Carpenter, 2003; Scheffer, 2009).

\section{Adaptive cycle, panarchy}

For social-ecological systems, the resilience approach uses a metaphor of the adaptive cycle to describe four commonly and subsequently occurring phases of change (Fig. 2a): The growth and the conservation phases form the fore loop of the cycle, the release and reorganization phases make up the back loop. The usually slow fore loop is characterized by growth and accumulation e.g. of biomass, but also of human and social capital. In contrast, the back loop is typically a rapid process marked by uncertainty, novelty and experimentation, leading either to destructive or creative change in the system. Many of the traditional cultural landscapes appear today to be within the realm of a late conservation phase, at the turning point into the back loop. While classical preservation efforts in the context of landscape research focus on the growth and conservation phases, the resilience approach draws attention to the processes of destruction and reorganization, providing a more complete view of system dynamics and specifically including the question of how to deal with breakdown and renewal. Adaptive cycles can be organized hierarchically at different scales across time and space, resulting in nested structures referred to as panarchy (Gunderson \& Holling, 2002) (Fig. 2b).

As Chapin III et al. (2009: 16) point out "adaptive cycles of change can occur at multiple levels of organizations, such as individuals, communities, watersheds, and regions. These adaptive cycles interact forming a panarchy. For example, dynamics at larger scales (e.g. migration dynamics or wealth) provide legacies, context and constraints that shape patterns of renewal (system memory). Dynamics at finer scales (e.g. insect population dynamics, household structure) may trigger release (revolt; e.g. insect outbreak)." Thus, nested smaller and faster cycles shaped through experimentation and learning allow for an adaptive, evolutionary development. Stabilizing interlinkages between the different cycles and many small steps of reorganization prevent cascading instabilities of the whole. 


\section{a. Adaptive cycle}

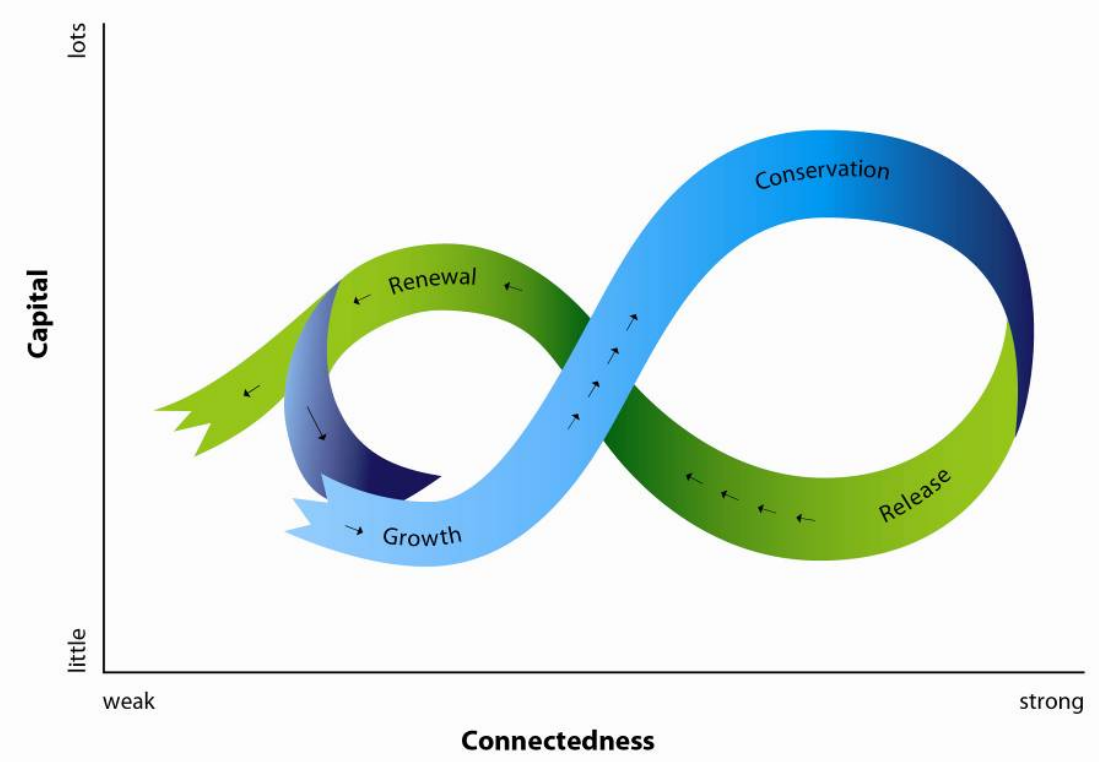

b. Panarchy

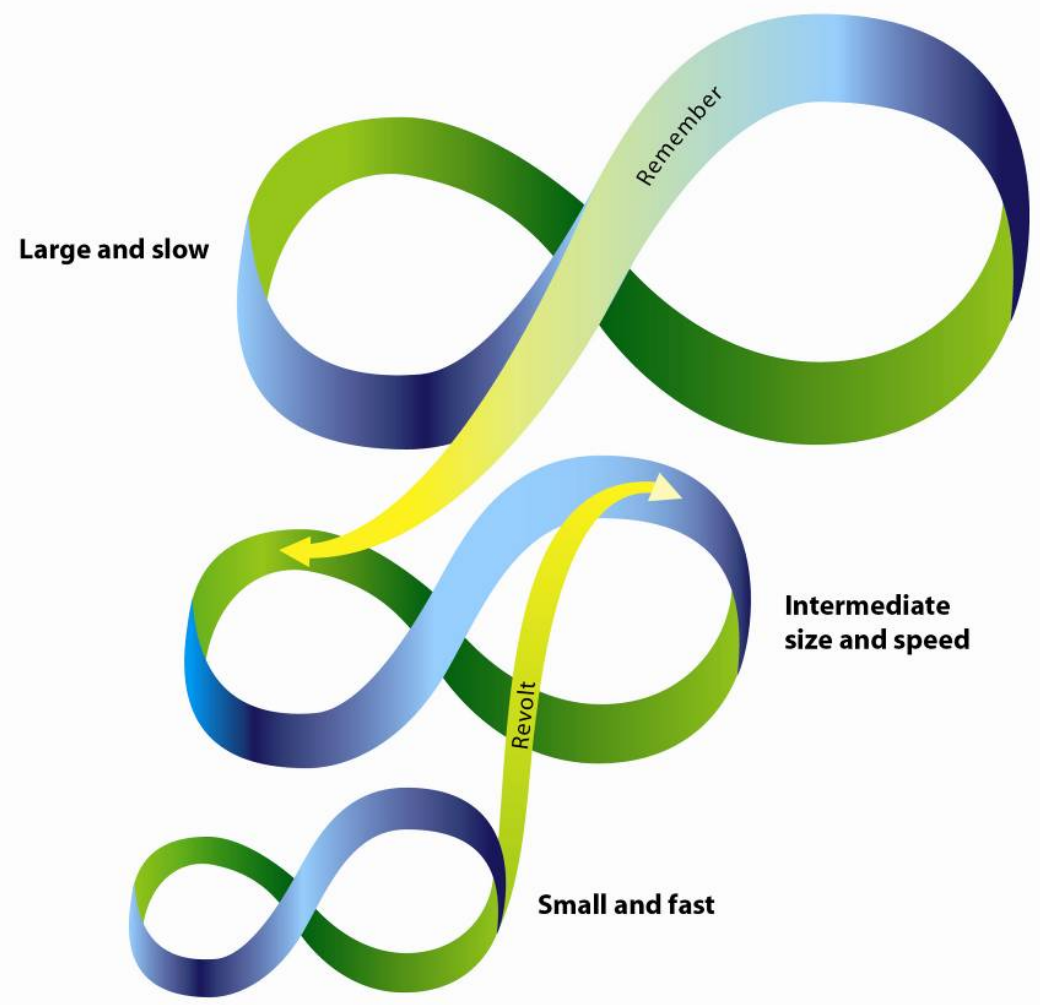

Fig 2. (a) Adaptive cycle and (b) cross-scale linkages among adaptive cycles (panarchy) in a social-ecological system (figure and description taken from Chapin III et al. 2009: 16).

\section{Adaptive co-management}

Regarding the management of social-ecological systems, the resilience perspective draws on the concept of adaptive management which is based on collaboration amongst multiple stakeholders. The overarching goal is not to prevent change, but to foster flexibility and adaptation through learning and constant improvement. For this, experimentation, monitoring 
and evaluation are essential. Learning-by-doing, collaboration and shared power between actors on the different spatial levels, enhancement of social capacity and inclusion of different knowledge systems are among the most prominent features of this approach. Adaptive comanagement is considered to be at the core of a sustainable development that enhances resilience in coupled human and natural systems. How to build resilience in practice and guidelines for adaptive co-management are outlined in a variety of case studies and handbooks (e.g. Berkes et al., 2003; Walker \& Salt, 2006a; Chapin III et al., 2009).

Resilience research attempts to identify the driving forces of the systems in question, to determine critical thresholds and to find ways to encourage resilience and to manage phases of reorganisation. Although resilience may be used as a descriptive concept, most researchers assign it normative content by assuming that management for resilience opens up desirable pathways for society, especially in changing environments where the future is unpredictable.

In summary, the resilience approach offers, on the one hand, concepts for comprehensive analysis and, on the other hand, instructions for directing a system towards desired pathways, i.e. ideas for the understanding as well as the management of change.

\section{Bringing together resilience and cultural landscape perspectives}

Both the resilience and the cultural landscape perspective share an interest in the understanding and management of landscape change. However, so far very few studies have integrated the approaches and existing knowledge of the two research communities. Consequently, the suitability of the resilience approach for the analysis of landscape dynamics remains vague.

The aim of crossing the border and closing this gap was the starting point for the plan to bring together scientists from both research communities to discuss the theoretical and practical use of the resilience perspective for the study of landscape change. The topic was placed at the centre of an international workshop organised by the Ecosystem Services Research Group at the Berlin-Brandenburg Academy of Sciences and Humanities, Freiburg University, Ecologic Institute and Öko-Institut (http://www.ecosystemservices.de) which took place in June 2010 in Berlin. The two-day workshop hosted 40 selected participants from the landscape and the resilience schools. By creating space for exchange and drawing on the case studies presented, we aimed to

- expand our understanding of how to conceptualize landscapes as social-ecological systems,

- take a closer look at driving forces of landscape change on various spatial and temporal scales,

- track long-term landscape change in terms of social-ecological resilience,

- analyze social capital as a source of resilience and adaptation in landscapes, and

- formulate strategies for adaptive management of cultural landscapes.

For this special issue we selected three workshop papers which address core features of the resilience approach: drivers of change, regime shifts and stakeholder-based adaptive management. This is embedded in case studies drawing on three very different regions and landscape-related problems. First, Christoph Schröder investigates drivers of landscape dynamics in the Dehesas of the Sierra Morena in Spain. Drawing on a political-ecologyapproach, he provides a rich analysis of the historic background and particularly the power relations and stakeholder perceptions which are at the heart of the processes of landscape change. Second, Maria Moorfeld takes us to Eastern Germany where landscapes are at a turning point. This paper investigates how different processes of change, namely demographic and economic change, result in the instability of the whole social-ecological system and thus contribute to a fundamental change, or regime shift. Finally, Traci Birge explores the possibilities for identifying stakeholders and involving them in the management of traditional rural biotopes in Finland - a key strategy in the management of social-ecological systems which are subject to undesired changes. Playing the role of stewards, local 
stakeholders help to enhance the resilience of these landscapes which are increasingly abandoned.

The papers illustrate how the resilience perspective can be integrated in landscape studies and point to the resulting benefits of this approach which crosses two research communities. In the light of these experiences, sharing knowledge and integrating the approaches seems fruitful: On the one hand, the resilience concept has much to offer for landscape research. It provides a systematic framework which allows one to distinguish fundamental forms of change from those which are less important for the functions and values of the landscapes (or socialecological systems) in question. The system approach also helps to address drivers and patterns of change in a comprehensive manner and thus provides a deeper understanding of change. Concerning management, the resilience concept and its co-adaptive management concept could help the landscape approach to develop more dynamic management approaches which constructively deal with change, instead of trying to prevent change at any cost. Landscape research tends to focus especially on conservation phases and mostly neglects the backloop of change. Consequently, there is much to learn from the resilience community concerning the question of how to respond to inevitable change.

However, the rewards of knowledge sharing are mutual, given that the landscape approach also has much to offer research on resilience: It can provide theories, methods and results for a rich analysis of human-nature relationships. This is especially true for the task of identifying and explaining drivers of change. In particular, much work has been done on identifying the different historical layers in landscapes - and these results should be used and considered in resilience research as these legacies create distinctive path dependencies. Finally, landscape research has a great deal to offer in cases where it is necessary to address the nonmaterial features of the human-nature relationship, for instance place-attachment or aesthetic and spiritual values all these factors are driven by human perception which makes them difficult to grasp, but they play a crucial role in coupled social-ecological systems. Here again, landscape research draws on rich experience and corresponding conceptual, methodological and empirical knowledge.

\section{Acknowledgements}

This publication and the Berlin workshop on social-ecological resilience of cultural landscapes were funded by the German Ministry of Education and Research within the Social-Ecological Research programme (FKZ $01 U U 0904$ A and B).

References

[1] Antrop, M. (2000). Changing patterns in the urbanized countryside of Western Europe. Landscape Ecology 15(3), 257-270. DOI: 10.1023/A:1008151109252

[2] Antrop, M. (2004). Landscape change and the urbanization process in Europe. Landscape and Urban Planning 67(1-4), 9-26. DOI:10.1016/S0169-2046(03)00026-4

[3] Antrop, M. (2005). Why landscapes of the past are important for the future. Landscape and Urban Planning 70(1-2), 21-34. DOI: 10.1016/j.landurbplan.2003.10.002

[4] Millennium Ecosystem Assessment (2005). Ecosystems and Human Well-being: Synthesis. Washington D.C.: Island Press.

[5] Berkes, F., Colding, J. \& Folke, C., Eds. (2003). Navigating Social-Ecological Systems: Building Resilience for Complexity and Change. Cambridge: Cambridge University Press.

[6] Bieling, C., Allgaier, M. \& Höchtl, F. (2010). Beyond agricultural production: forest expansion and the preservation of open landscapes in marginal areas. A case study from the Black Forest, Germany. Outlook on Agriculture 39(1), 25-30.

DOI: $10.5367 / 000000010791169989$ 
[7] Carpenter, S., Walker, B., Anderies, M. J. \& Abel, N. (2001). From metaphor to measurement: Resilience of what to what? Ecosystems 4(8), 765-781. DOI: 10.1007/s10021-001-0045-9

[8] Chapin III, S. F., Kofinas, G. P. \& Folke, C., Eds. (2009). Principles of Ecosystem Stewartship: Resilience-Based Natural Resource Management in a Changing World. New York: Springer.

[9] Figueroa, E. B. \& Aronson, J. (2006). New linkages for protected areas: Making them worth conserving and restoring. Journal for Nature Conservation 14, 225-232. DOI: 10.1016/j.jnc.2006.04.007

[10] Grove, A. T. \& Rackham, O. (2001). The Nature of Mediterranean Europe: An Ecological History. New Haven, London: Yale University Press.

[11] Gunderson, L. H. \& Holling, C. S., Eds. (2002). Panarchy: Understanding Transformations in Human and Natural Systems. Washington, Covelo, London: Island Press.

[12] Höchtl, F., Jenne, P., Petit, C. \& Konold, W. (2009). Stein und Wein I: Erhaltung und Entwicklung historischer Terrassenweinberge. Stadt+Grün 58, 23-28.

[13] Joneswalters, L. (2008). Biodiversity in multifunctional landscapes. Journal for Nature Conservation 16(2), 117-119. DOI: 10.1016/j.jnc.2008.03.001

[14] Kristensen, L. (2001). Agricultural change in Denmark between 1982 and 1989: the appearance of post-productivism in farming? Geografisk Tidsskrift 101(1), 77-86.

[15] Plieninger, T. \& Gaertner, M. (2011). Harnessing degraded lands for biodiversity conservation. Journal for Nature Conservation 19(1), 18-23.

DOI: 10.1016/j.jnc.2010.04.001

[16] Scheffer, M. (2009). Critical Transitions in Nature and Society. Princeton, Oxford: Princeton University Press.

[17] Scheffer, M. \& Carpenter, S. R. (2003). Catastrophic regime shifts in ecosystems: linking theory to observation. Trends in Ecology \& Evolution 18(12), 648-656. DOI: 10.1016/j.tree.2003.09.002

[18] Selman, P. \& Knight, M. (2006). On the nature of virtuous change in cultural landscapes: exploring sustainability through qualitative models. Landscape Research 31(3), 295-307. DOI: 10.1080/01426390600783517

[19] Stanners, D. \& Bourdeau, P., Eds. (1995). Europe's Environment: The Dobris Assessment. Copenhagen: European Environmental Agency.

[20] Vos, W. \& Klijn, J. (2000). Trends in European landscape development: prospects for a sustainable future. In J. Klijn \& W. Vos (Eds.), From Landscape Ecology to Landscape Science (pp. 3-29), Dordrecht: Kluwer Academic Publishers.

[21] Walford, N. (2003). Productivism is allegedly dead, long live productivism. Evidence of continued productivist attitudes and decision-making in South-East England. Journal of Rural Studies 19(4), 491-502. DOI: 10.1016/S0743-0167(03)00030-5

[22] Walker, B. H. \& Salt, D. (2006a). Building resilience in the wetlands: The Kristianstads Vattenrike, Sweden. In B. H. Walker \& D. Salt, Resilience Thinking: Sustaining Ecosystems and People in a Changing World (pp. 125-138), Washington DC: Island Press.

[23] Walker, B. H. \& Salt, D. (2006b). Resilience Thinking: Sustaining Ecosystems and People in a Changing World. Washington DC, Island Press.

[24] Walker, B. H., Gunderson, L. H., Kinzig, A. P., Folke, C, Carpenter, S. R. \& Schultz, L. (2006). A handful of heuristics and some propositions for understanding resilience in social-ecological systems. Ecology and Society 11, 13. Available at http://www.ecologyandsociety.org/vol11/iss1/art13/ 
[25] Zimmermann, R. C. (2006). Recording rural landscapes and their cultural associations: some initial results and impressions. Environmental Science \& Policy 9(4), 360-369. DOI: 10.1016/j.envsci.2006.01.009 